Observational Report

\title{
Opioid-Sparing Effect of Intravenous Outpatient Ketamine Infusions Appears Short-Lived in Chronic-Pain Patients with High Opioid Requirements
}

Leo Kapural, MD, PhD, Miranda Kapural, MD, Toula Bensitel, MD, and Daniel I. Sessler, MD

From: Departments of Pain Management and Outcomes

Research, Cleveland Clinic, Cleveland, $\mathrm{OH}$.

Dr. Leo Kapural is Professor of Anesthesiology, CCLCM at Case

Western, Pain Management Department, Cleveland Clinic, Cleveland, $\mathrm{OH}$.

Dr. Miranda Kapural is an anesthesiologist with the Cleveland Clinic, Cleveland, $\mathrm{OH}$.

Dr. Bensitel is with the Department of Pain Management, Cleveland Clinic, Cleveland, $\mathrm{OH}$.

Dr. Sessler is Chair of the Department of Outcomes Research, Cleveland Clinic, Cleveland, $\mathrm{OH}$.

Address correspondence: Leo Kapural, MD, PhD Carolinas Pain Institute 145 Kimel Park Drive, Suite 330

Winston-Salem, NC 27103

E-mail: Kapural@ameritech.net

Disclaimer: There was no external funding in the preparation of this manuscript.

Conflict of interest: None.

Manuscript received: 04/14/2010 Accepted for publication: $06 / 03 / 2010$

Free full manuscript: www.painphysicianjournal.com
Background and Objectives: Ketamine is opioid-sparing. It attenuates the onset of opioid tolerance, and suppresses opioid-induced hyperalgesia. This study evaluated whether or not repeated outpatient infusions of intravenous ketamine reduced the amount of pain and the amount of opioid requirements for patients suffering with chronic, noncancerous pain.

Study Design: Retrospective study

Setting: Outpatient pain clinic

Methods: We reviewed the records of 18 patients taking high doses of opioids chronically and nonetheless reporting poorly controlled pain. A comparison control group of 18 similar patients with high opioid requirements who were not given ketamine were selected from our clinic population.

Intervention: Intravenous ketamine infusions

Measurement: VAS pain scores and opioid use

Results: Morphometric and demographic characteristics, baseline opioid use, and pain scores were similar in the ketamine and comparison groups. Five patients given ketamine experienced no benefit and discontinued treatment after 1-2 infusions. One patient developed a supraventricular arrhythmia which immediately resolved upon cessation of the infusion. And another, despite pain relief, felt overly-anxious and opted out. Eleven patients thus completed 3-6 weekly ketamine infusions. At 6 months, 5 patients maintained less than $50 \%$ of their baseline opioid use, while the remaining patients returned to the baseline opioid use or increased their requirements. There was no significant difference in pain scores at 6 months in patients who received ketamine infusions and control group patients.

Limitations: Retrospective nature of the study

Conclusions: Outpatient intravenous ketamine infusions did not improve long-term pain scores in patients with high opioid requirements and only a few were able to substantially reduce opioid use. Considering infusion risks and cost of such outpatient treatment, ketamine infusions do not appear to be a feasible option for improving pain relief and decreasing opioid use in high-opioid requirement patients.

Key words: Ketamine; anesthesia; chronic pain; opioids; continuous infusion; opioid requirements

Pain Physician 2010; 13:389-394 
K etamine is a non-competitive antagonist of NMDA (N-methyl-D-asparate) receptors that can also act on a variety of receptors (nicotinic, muscarinic, and opioid) and channels ( $\mathrm{Na}+$ and $\mathrm{Ca2+)}$ (1). It has been used as an anesthetic for the past 35 years. Ketamine is also an effective analgesic in a variety of clinical settings (1-5), and is opioid-sparing in post-surgical (6) and other (7) settings. Additionally, ketamine attenuates the onset of opioid tolerance (710) and suppresses opioid-induced hyperalgesia (1113). Ketamine-induced analgesia has been successfully achieved when the drug is given intravenously (14-22).

Ideally, ketamine infusions should provide longterm pain relief and decrease opioid use, preferably in outpatient environments to keep costs relatively low. The excessive costs of low-dose ketamine infusion trials conducted over many days in an inpatient setting (22) and/or anesthetic-dose ketamine infusions in intensive care settings (19) would be a major obstacle to making this approach routine. Furthermore, recent studies suggested that the prolonged low-dose ketamine infusion (i.e., 4.2 days) might improve pain scores only over a short period, such as 12 weeks, in patients with CRPS (22). And finally, anesthetic-dose ketamine infusions might be risky (19).

Currently it remains unclear if repeated outpatient ketamine infusions provide long-term pain relief in patients with high opioid requirements. The opioid-sparing effect of ketamine has been extensively studied in post-operative pain patients (21), but not in chronic pain patients. We thus evaluated whether repeated 3-6 weekly infusions of high-dose intravenous ketamine in an outpatient setting reduces long-term pain relief and reduces opioid requirements in patients with chronic non-malignant pain that is poorly controlled despite high-dose opioid use.

\section{Methods}

With approval from the Internal Review Board (IRB), the records of 18 consecutive patients given ketamine infusions were reviewed. Each patient was chronically taking high-dose opioids (Table 1) for nociceptive or neuropathic conditions. The opioids included controlled-release forms of Class II agents such as morphine, oxycodone, or fentanyl; some also took shortacting forms of oral opioids for breakthrough pain.

All patients had drastically increased their opioid requirements over the previous 12 months but still had an average daily pain score exceeding $5 \mathrm{~cm}$ on a $0-10$ $\mathrm{cm}$ verbal response scale $(0 \mathrm{~cm}$ indicating no pain and
$10 \mathrm{~cm}$ being the worst imaginable pain). Patients with a history of ischemic heart disease, tachyarrhythmia, uncontrolled hypertension or a history of psychological issues were not considered for the ketamine infusion treatment.

Patients were counseled on the side effects of ketamine infusion, including light-headedness, dizziness, headache, feeling tired, sedation, dream-like state, vivid dreams, increased distractibility, and disorientation. Physiological side effects such as tachycardia, increased blood pressure, nystagmus, hypersalivation, increased urinary output, decreased sensitivity to pain, amnesia, slurred speech, and lack of coordination were also disclosed.

Patients were given 2-4 mg of midazolam just before initiation of each ketamine infusion, and an additional 2-4 mg if needed during infusions. Generally, the ketamine infusions were initiated at the rate of $10 \mathrm{mg} /$ hour. The rate was increased as tolerated until patients reported no pain or until the infusion rate reached 100 $\mathrm{mg} / \mathrm{hour}$. Once an effective infusion rate was identified, it was continued for 3 hours or as long as tolerated. When unacceptable side effects were noted, the rate was decreased or the infusion was completely/temporarily discontinued. Patients were expected to receive between 3 and 6 weekly infusions.

A comparison group of 18 patients with the same sex distribution (10 men and 8 women) was retrospectively assembled from the physician-assistant opioid-refill schedule of chronic-pain patients. Patients who were receiving $>80 \mathrm{mg}$ per day of $\mathrm{MSO} 4$ equivalent and had pain for $>1$ year were selected (also see the first paragraph in Results and Table 1). Patients in both groups experienced a comparable duration of chronic pain and their baseline pain scores $(P=0.62)$ and baseline opioid daily requirements $(P=0.173) \mathrm{mg}$ were comparable (Table 1).

Demographic characteristics, pain intensity and duration, and opioid use were obtained for patients in the ketamine infusion and comparison groups. Pain was evaluated using a 0-10-point verbal response score with 0 indicating no pain and 10 being the worst imaginable pain. In the ketamine treatment patients, pain scores and opioid use (in morphine sulfate equivalents) were recorded before beginning the first infusion, after completing the series of infusions, and 6 months later. In the comparison group, pain scores were compared at 8-month intervals to approximate the follow-up interval of the group who received ketamine infusion. 
Ketamine for Chronic Pain

Table 1. Characteristics of the patients who underwent a series of ketamine intravenous infusions.

\begin{tabular}{|c|c|c|c|c|c|c|c|c|c|c|}
\hline $\begin{array}{l}\text { Patient } \\
\text { Number }\end{array}$ & Age & Sex & Diagnosis & $\begin{array}{c}\text { Chronic } \\
\text { pain } \\
\text { (years) }\end{array}$ & $\begin{array}{l}\text { Ketamine } \\
\text { infusions } \\
\text { (number) }\end{array}$ & $\begin{array}{c}\text { Highest } \\
\text { ketamine } \\
\text { infusion } \\
\text { rate }(\mathrm{mg} / \mathrm{h})\end{array}$ & $\begin{array}{c}\text { VRS } \\
\text { pain } \\
\text { before } \\
\text { infusion }\end{array}$ & $\begin{array}{l}\text { VRS pain } \\
\text { score } 6 \\
\text { months } \\
\text { later }\end{array}$ & $\begin{array}{c}\text { Opioid use } \\
\text { (mg MSO4 } \\
\text { equivilants) } \\
\text { before } \\
\text { infusion } \\
\end{array}$ & $\begin{array}{c}\text { Opioid use } \\
\text { (mg MSO4 } \\
\text { equivilants) } \\
6 \text { months } \\
\text { later } \\
\end{array}$ \\
\hline 1 & 28 & $\mathrm{M}$ & Neuralgia & 4 & 3 & 100 & 8 & 8 & 100 & 100 \\
\hline 2 & 46 & $M$ & CRPS 1 & 5 & 1 & 80 & 4 & 6 & 396 & 396 \\
\hline 3 & 46 & M & CLBP & 7 & 6 & 100 & 7 & 7 & 540 & 510 \\
\hline 4 & 25 & $\mathrm{~F}$ & CLBP & 3 & 1 & 75 & 8 & 8 & 220 & 220 \\
\hline 5 & 42 & M & CAP & 3 & 2 & 50 & 7 & 7 & 270 & 300 \\
\hline 6 & 24 & $\mathrm{~F}$ & Neuropathy & 3 & 6 & 40 & 10 & 7 & 150 & 25 \\
\hline 7 & 50 & M & CLBP & 10 & 3 & 50 & 4 & 4 & 80 & 80 \\
\hline 8 & 61 & $\mathrm{~F}$ & Neuropathy & 30 & 1 & 50 & 8 & 8 & 120 & 200 \\
\hline 9 & 45 & M & PLS & 4 & 3 & 50 & 7 & 7 & 150 & 150 \\
\hline 10 & 36 & $\mathrm{~F}$ & CAP & 2 & 6 & 100 & 10 & 5 & 160 & 120 \\
\hline 11 & 53 & M & Neuropathy & 3 & 3 & 100 & 10 & 9 & 250 & 250 \\
\hline 12 & 30 & $\mathrm{~F}$ & PLS & 9 & 3 & 100 & 10 & 3 & 80 & 0 \\
\hline 13 & 52 & $\mathrm{~F}$ & CAP & 20 & 3 & 90 & 4 & 2 & 80 & 0 \\
\hline 14 & 69 & $\mathrm{~F}$ & PLS & 11 & 1 & 35 & 10 & 7 & 82 & 52 \\
\hline 15 & 31 & $\mathrm{~F}$ & CLBP & 8 & 1 & 100 & 8 & 9 & 174 & 70 \\
\hline 16 & 38 & $\mathrm{M}$ & CLBP & 6 & 2 & 100 & 8 & 9 & 118 & 45 \\
\hline 17 & 42 & M & CLBP & 20 & 6 & 60 & 7 & 8 & 190 & 150 \\
\hline 18 & 48 & $\mathrm{M}$ & CRPS 1 & 7 & 4 & 50 & 4 & 4 & 247 & 150 \\
\hline
\end{tabular}

CRPS 1 - Complex Regional Pain Syndrome type 1; CAP- Chronic Abdominal Pain; CLBP-Chronic Lower Back Pain; PLS- Post-laminectomy syndrome. VRS is verbal response pain score on a $0-10$ scale $(0=$ no pain; $10=$ worst imaginable pain).

To evaluate differences between the various values, Mann-Whitney Rank Sum Test was used. Statistical tests and graphs were produced using Sigma Plot software (Systat Software Inc., Chicago, IL). Results are presented as means \pm SDs unless otherwise specified.

\section{Results}

The mean age of the comparison group was $46 \pm$ 10 (median 46 ) years vs. the ketamine group mean age of $45 \pm 12$ (median 44 ) years. There were 10 men and 8 women in each of the groups. Patients in each group experienced a comparable duration of chronic pain: 10 \pm 9 years vs. $9 \pm 8$ years for the group who received ketamine infusion. Their pain scores $(7 \pm 2$ vs. $7 \pm 2)$ and opioid daily requirements $(153 \pm 158$ (median 93) mg morphine sulfate equivalents vs. $190 \pm 121$ (median 155) $\mathrm{mg}$ were comparable (Table 1 ).

Five of the 18 patients treated with ketamine infusions experienced no beneficial effect after one or 2 infusions and therefore opted not to receive additional infusions. One patient developed a supraventricular ar- rhythmia, which reversed upon immediate cessation of the infusion. One other patient, despite good analgesia, felt overly anxious and experienced unpleasant dreams, and thus opted not to have another infusion. Eleven patients thus completed 3-6 weekly ketamine infusions. A total of 55 infusion cycles were given among all 18 patients. The peak infusion rate given varied from 35 to $100 \mathrm{mg} /$ hour (Table 1). There were a few side affects such as dizziness and sleepiness. All of the patients were released without difficulties from our outpatient pain management center.

Baseline pain scores in the 11 patients given 3-6 ketamine infusions were $8 \pm 2$. Immediately after the last ketamine infusion, pain was 0 , but at 6 months returned to $7 \pm 2$ which did not differ significantly from baseline scores $(P=0.13)$ (Fig. 1).

In the 11 patients who received 3-6 ketamine infusions, opioid use decreased following the last infusion visit (1-1.5 months follow-up) (Fig. 2) from $184 \pm 133$ mg morphine sulfate equivalents ( $150 \mathrm{mg}$ median) to $92 \pm 100 \mathrm{mg}$ (60 mg median), and the decrease was 


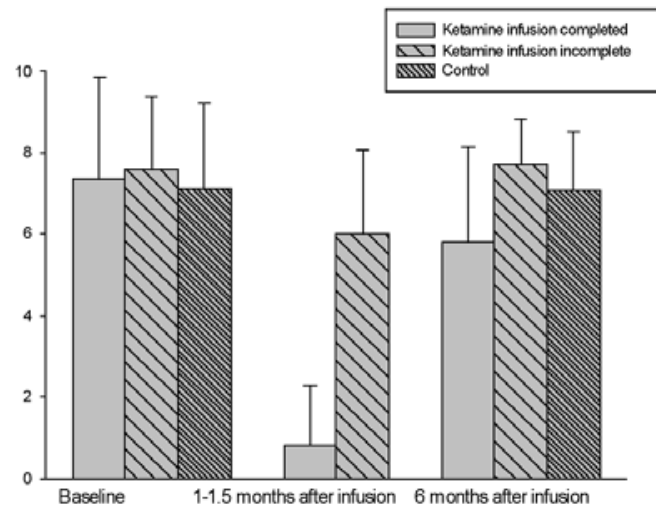

Fig. 1. Changes in the verbal pain scores (on a 0-to-10 scale) just before, immediately after, and 6 months after completion of a series of ketamine infusions in 11 patients who completed a series of 3-6 infusions, 5 who started but never completed, and the control group $(n=18)$. There was no significant difference between the mean baseline pain scores of those who did and did not received ketamine infusions $(P=0.181)$. There was a significant decrease in the verbal pain scores after completion of the ketamine infusion series $(P<0.001)$, but it was not sustained at 6 months $(P=$ $0.17)$.

statistically significant $(P=0.015)$. Six months after the final ketamine infusion, the difference was no longer statistically significant with opioid use returning to $140 \pm 144 \mathrm{mg}$ morphine sulfate equivalents (120 mg median) ( $P=0.274$; Fig. 2). Six months after completing the ketamine infusion cycles, 5 patients maintained less than $50 \%$ of their baseline opioid use. Two among these 5 patients also reported a $>50 \%$ improvement in their verbal pain scores. However, the remainder of the patients returned to the baseline dose or even increased their opioid use.

\section{Discussion}

Several recent studies report successful short-term treatment of chronic pain from complex regional pain syndromes with ketamine infusions $(19,20,22-24)$. Unfortunately, improvements were only reported over 212 weeks, and the studies failed to document long-term benefit. Furthermore, ketamine was given to inpatients as a subanesthetic, low-dose infusion with a gradual titration $(20,22)$. Such lengthy infusions are expensive and are seldom reimbursed by third-party payers. We thus tried relatively short outpatient infusions which do not require hospitalization.

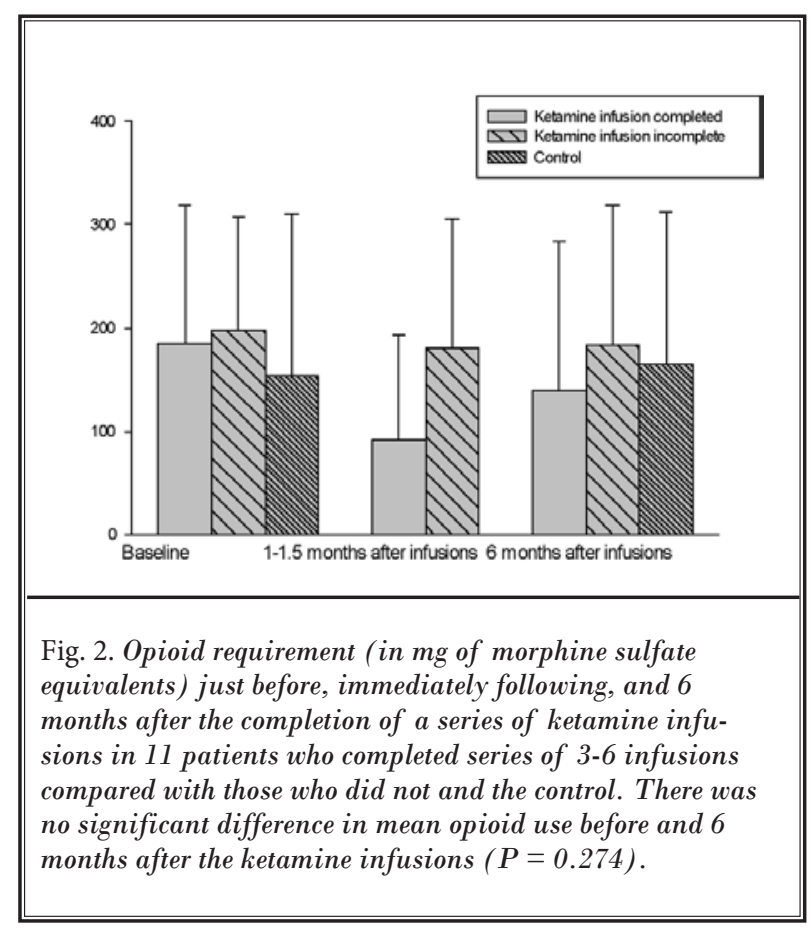

In general, we could not demonstrate significant improvement in pain scores or opioid consumption in most treated patients (Fig. 1). Furthermore, 7 of 18 patients who received an initial ketamine infusion never even completed the planned series of 3-6 infusions either because of the side effects or, more commonly, because they perceived no apparent benefit. Consequently, only 5 of 11 patients who received the entire series of ketamine infusions maintained significantly decreased opioid use 6 months after completing treatment. It seems unlikely that this modest response in a small fraction of the 18 initial patients justifies the approach we tested.

High-dose desensitization with ketamine infusions of 5-7 mg/kg/hour for 5-7 days have been used in patients with complex regional pain syndrome (19). However, this anesthetic-dose approach requires patients to be admitted to an intensive-care unit. Considering the costs of inpatient infusions, especially in an intensive care unit, this approach cannot be considered feasible unless considerable long-term benefit is demonstrated and proven safe.

We included patients with poorly controlled pain, despite taking high doses of opioids. Most had several opioid rotations prior to ketamine treatment, but still had relatively high opioid intake (from 80 to $540 \mathrm{mg}$ of morphine sulfate equivalents). These were patients 
who were generally doing poorly under conventional therapy for the chronic pain, and were the population most likely to benefit from ketamine infusions and justify the concomitant expense. The comparison group was similar in important respects, especially with regard to pain experience and opioid consumption. Regarding the variability of the patient group studied and the control group, such diversity of the causes of the chronic pain in either group should not be an issue considering the ketamine mechanism of action. Ketamine is a non-competitive antagonist of $\mathrm{N}$-methyl-D-asparate (NMDA) receptors and can also act on a variety of other receptors (nicotinic, muscarinic, and opioid) and ion channels ( $\mathrm{Na}+$ and $\mathrm{Ca} 2+$ ).

The major weakness of this retrospective study is lack of randomization. However, the intention behind reviewing our data was to determine whether a randomized study was likely to be worthwhile. That does not appear to be the case. We also cannot comment on the mechanism of action of the ketamine opioid-spar- ing effect in the 5 patients who maintained improved analgesia 6 months after the completion of thisseries of infusions. However, it might be the result of long-term suppression of opioid-induced hyperalgesia. It is equally likely, though, that some patients worsen over time and some improve. Focusing on the 5 patients who ultimately improved thus ignores the 13 who either didn't complete the infusions or didn't improve. Our results should thus be considered negative, rather than effective, in the population as a whole

In conclusion, repeated ambulatory intravenous ketamine infusions did not consistently produce longterm reductions in pain or opioid use in patients with severe chronic pain.

\section{Acknowledgments}

The authors wish to thank the editorial board of Pain Physician for review and criticism in improving the manuscript.

\section{References}

1. Schmid RL, Sandler AN, Katz J. Use and efficacy of low-dose ketamine in the management of acute postoperative pain: A review of current techniques and outcomes. Pain 1999; 82:111-125.

2. Hocking G, Cousins MJ. Ketamine in chronic pain management: An evidence-based review. Anesth Analg 2003; 97:1730-1739.

3. Kohrs R, Durieux ME. Ketamine: Teaching an old drug new tricks. Anesth Analg 1998; 87:1186-1193.

4. Taura P, Fuster J, Blasi A, Martinez-Ocon J, Anglada T, Beltran J, Balust J, Tercero J, Garcia-Valdecasas JC. Postoperative pain relief after hepatic resection in cirrhotic patients: The efficacy of a single small dose of ketamine plus morphine epidurally. Anesth Analg 2003; 96:475480.

5. Weinbroum AA. A single small dose of postoperative ketamine provides rapid and sustained improvement in morphine analgesia in the presence of morphine-resistant pain. Anesth Analg 2003; 96:789-795.

6. Chapman V, Dickenson AH. The combination of NMDA antagonism and mor- phine produces profound antinociception in the rat dorsal horn. Brain Res 1992; 573:321-323.

7. Bell RF. Low-dose subcutaneous ketamine infusion and morphine tolerance. Pain 1999; 83:101-103.

8. De Simoni MG, Giglio R, Dal TG, Conforti I, Algeri S. Cross tolerance between ketamine and morphine to some pharmacological and biochemical effects. Neuropharmacology 1985; 24:541-545.

9. Kissin I, Bright CA, Bradley EL, Jr. The effect of ketamine on opioid-induced acute tolerance: Can it explain reduction of opioid consumption with ketamine-opioid analgesic combinations? Anesth Analg 2000; 91:1483-1488.

10. Laulin JP, Maurette P, Corcuff JB, Rivat C, Chauvin M, Simonnet G. The role of ketamine in preventing fentanyl-induced hyperalgesia and subsequent acute morphine tolerance. Anesth Analg 2002; 94:1263-1269.

11. Celerier E, Rivat C, Jun Y, Laulin JP, Larcher A, Reynier P, Simonnet G. Long-lasting hyperalgesia induced by fentanyl in rats: Preventive effect of ketamine. Anesthesiology 2000; 92:465-472.
12. Luginbuhl M, Gerber A, Schnider TW, Petersen-Felix S, rendt-Nielsen L, Curatolo $M$. Modulation of remifentanilinduced analgesia, hyperalgesia, and tolerance by small-dose ketamine in humans. Anesth Analg 2003; 96:726732.

13. Bristow A, Orlikowski C. Subcutaneous ketamine analgesia: Postoperative analgesia using subcutaneous infusions of ketamine and morphine. Ann R Coll Surg Engl 1989; 71:64-66.

14. Clausen L, Sinclair DM, Van Hasselt $\mathrm{CH}$. Intravenous ketamine for postoperative analgesia. S Afr Med J 1975; 49:1437-1440.

15. Kararmaz A, Kaya S, Karaman H, Turhanoglu S, Ozyilmaz MA. Intraoperative intravenous ketamine in combination with epidural analgesia: Postoperative analgesia after renal surgery. Anesth Analg 2003; 97:1092-1096.

16. Lauretti GR, Azevedo VM. Intravenous ketamine or fentanyl prolongs postoperative analgesia after intrathecal neostigmine. Anesth Analg 1996; 83:766770.

17. Mercadante S, Arcuri E, Tirelli W, Ca- 
succio A. Analgesic effect of intravenous ketamine in cancer patients on morphine therapy: A randomized, controlled, double-blind, crossover, double-dose study. J Pain Symptom Manage 2000; 20:246-252.

18. Mitchell AC, Fallon MT. A single infusion of intravenous ketamine improves pain relief in patients with critical limb ischaemia: Results of a double blind randomised controlled trial. Pain 2002; 97:275-281.

19. Koffler SP, Hampstead BM, Irani F, Tinker J, Kiefer RT, Rohr P, Schwartzman RJ. The neurocognitive effects of 5 day an- esthetic ketamine for the treatment of refractory complex regional pain syndrome. Arch Clin Neuropsychol 2007; 22:719-729.

20. Goldberg ME, Domsky R, Scaringe D, Hirsh R, Dotson J, Sharaf I, Torjman MC, Schwartzman RJ. Multi-day low dose ketamine infusion for the treatment of complex regional pain syndrome. Pain Physician 2005; 8:175-179.

21. Bell RF, Dahl JB, Moore RA, Kalso E. Perioperative ketamine for acute postoperative pain. Cochrane Database Syst Rev 2006; 25:CDoo4603.
22. Sigtermans MJ, van Hilten JJ, Bauer MCR, Arbous MS, Marinus J, Sarton EY, Dahan A. Ketamine produces effective and long-term pain relief in patients with Complex Regional Pain Syndrome Type 1. Pain 2009; 145:304-311.

23. Corell GE, Maleki J, Gracely EJ, Muir JJ, Harbut RE. Subanesthetic ketamine infusion therapy: A retrospective analysis of a novel therapeutic approach to complex regional pain syndrome 2004; 5:263-275.

24. Bell RF. Ketamine for chronic, non-cancer pain. Pain 2009;141:210-214. 